\title{
Fatigue of Tooth-colored Restoratives in Aqueous Environment
}

\author{
Yoshiko KAWAKAMI, Fumio TAKESHIGE, Mikako HAYASHI and Shigeyuki EBISU \\ Department of Restorative Dentistry and Endodontology, Osaka University Graduate School of Dentistry, 1-8 Yamadaoka, \\ Suita, Osaka 565-0871, Japan \\ Corresponding author, Y. KAWAKAMI; E-mail: kawakamy@dent.osaka-u.ac.jp
}

Received June 9, 2006/Accepted September 22, 2006

\begin{abstract}
The purpose of this study was to investigate the interaction between mechanical and chemical fatigue in resin composites and dental ceramics, and the effects thereof on fatigue resistance of tooth-colored restoratives. To this end, the fatigue fracture resistance of restoratives under dry and aqueous conditions were analyzed by a dynamic fatigue crack propagation test using beam-shaped specimens with a precrack. Fatigue crack propagation characteristics were expressed by the correlation between fatigue crack growth rate $(\mathrm{da} / \mathrm{dN})$ and stress intensity factor range $(\Delta \mathrm{K})$. In addition, fatigue crack growth threshold $\left(\Delta \mathrm{K}_{\mathrm{th}}\right)$ was calculated. Following the fatigue test, a fractographic examination was performed using scanning electron microscopy. Fatigue crack initiation was retarded in resin composites under aqueous condition, but dental ceramics were susceptible to slow crack growth after crack initiation. SEM images of the fatigue facture surfaces reflected inorganic and organic filler particles of different sizes in composites and the bonding at crystal-glass interface in ceramics. It was concluded that water exerted different effects on the fatigue resistance of composites and ceramics.
\end{abstract}

Keywords: Fatigue, Dental ceramic, Resin composite

\section{INTRODUCTION}

In the oral environment, fatigue fracture of dental restoratives can be induced by relatively weak and repetitive loads, such as the force arising from ordinary chewing ${ }^{1,2}$. For resin composites, several mechanisms may participate in fatigue-induced damage of resin composite materials, which include matrix cracking, matrix deformation, void formation, multidirectional cracking, filler debonding, and filler failure $^{2)}$. For dental ceramics, experimental difficulties associated with their extreme brittleness have prevented their fatigue behavior to be sufficiently represented-but recent studies have proven that they are affected by both mechanical and chemical fatigue $^{3-8}$. Fatigue fracture of resin composites and dental ceramics originates from an internal or external microflaw, from which cracks propagate and eventually result in a complete catastrophic fracture $^{2,9)}$. However, inevitably, flaws that can trigger crack initiation are introduced during the fabrication of composites and ceramics as well as during the restoration procedure. Therefore, the characteristics of fatigue crack propagation, expressed in terms of fatigue crack growth rate $(d \mathrm{a} / d \mathrm{~N})$ and stress intensity factor range $\Delta K$ ), are appropriate for evaluating the fatigue resistance of dental restoratives. Likewise, it is appropriate for fatigue crack initiation to be expressed in terms of fatigue crack growth threshold $\left(\Delta \mathrm{K}_{\mathrm{th}}\right)$.

Currently, dynamic fatigue crack propagation test for resin composites is conducted using a com- pact tension specimen in the form of a double cantilever beam ${ }^{10-13)}$. However, a suitable fatigue crack propagation test for dental ceramics has not been established, largely due to the difficulty associated with fabricating a relatively large specimen with a complicated shape. Therefore, to date, only static fatigue test with indentation has been used to evaluate fatigue crack propagation in dental ceramics ${ }^{4,5)}$. However, dynamic fatigue crack propagation tests are presumably more appropriate than static fatigue tests for evaluating the fatigue resistance of dental restoratives ${ }^{14)}$, since fatigue resistance is overestimated under static loading ${ }^{9)}$. Against this background, the present study set out to conduct the first dynamic fatigue crack propagation test for dental ceramics using beam-shaped specimens with a precrack, which were fabricated by a Compression Bridge Assembly (Fig. 1).

Aging in water or aqueous fluids is well known to decrease the fatigue resistance of polymer-based composites as a result of water absorption by the matrix $^{15)}$. However, inconsistencies in fatigue crack propagation behavior of composites under aqueous conditions have been reported ${ }^{10-12,17}$. In our previous investigation $^{13)}$, it was confirmed that contrary to common perception on fatigue fracture behavior of resin composites, fatigue crack propagation in resin composites was retarded under aqueous conditions but accelerated after water immersion. This indicated that the adverse effect of water on fatigue resistance of composites was dependent on experimental conditions. Moreover, fatigue cracks detoured 
around inorganic macrofillers but penetrated organic fillers, suggesting that inorganic macrofillers were instrumental to retarding fatigue cracks in resin composites.

In industrial ceramics, the deleterious effect of slow crack propagation can be attributed to a stressenhanced chemical reaction, known as "stress corrosion", that occurs in the presence of water vapor at a crack tip ${ }^{16}$. However, the effects of water on dynamic crack propagation in dental ceramics have not been confirmed. Therefore, there is a need to investigate the interaction between mechanical and chemical fatigue in dental ceramics and clarify their respective roles in fatigue behavior in the oral environment, and thereby compare the results against resin composites.

The present study investigated the fatigue fracture mechanism of tooth-colored restoratives by conducting dynamic fatigue crack propagation test followed by fractographic examination. The null hypothesis in this study was that crack propagation in resin composites and dental ceramics was not affected

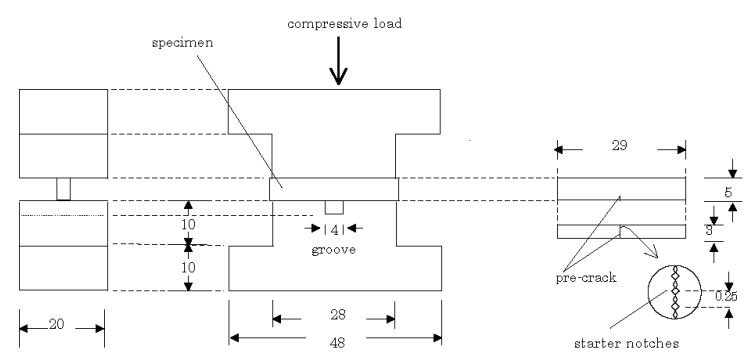

Fig. 1 Bridge compression assembly. Specimen with starter notches on the surface of the tension side was held by metallic jigs. Compression load was applied to the upper surface of specimen to initiate a precrack until the vertical length of the crack was approximately $1 \mathrm{~mm}$. Unit: $\mathrm{mm}$. by the presence of water.

\section{MATERIALS AND METHODS}

\section{Preparation of specimens}

Beam-shaped specimens measuring $3.0 \times 5.0 \times 10.0$ $\mathrm{mm}$ were fabricated from resin composites and dental ceramics (Table 1). Specimens for heat-pressed and castable ceramics were fabricated according to the manufacturers' instructions, and resin composite specimens were light-cured for 14 minutes in a custom-made metallic mold. All specimens were polished with 1500-grit $\mathrm{SiC}$ paper followed by $1-\mu \mathrm{m}$ alumina particles on a water-irrigated grinding wheel (Ecomet III, Buehler Ltd., Lake Bluff, IL, USA) to eliminate superficial microflaws. The edges of all the beam specimens were ground.

Starter notches to introduce a precrack were created by applying a vertical load of $10 \mathrm{~N}$ for $30 \mathrm{sec}-$ onds with a Knoop stylus, followed by an additional vertical load of $50 \mathrm{~N}$ for 10 seconds with a Vickers stylus. Two kinds of indentation were performed so as to obtain a precrack in a straight form. Three starter notches were then arranged at the center on the tension side of each beam specimen at $0.25-\mathrm{mm}$ intervals (Fig. 1). Next, a precrack - which connected the starter notches and which propagated over the whole surface of the tension side with a maximum depth of $1 \mathrm{~mm}$ - was initiated by applying a compression load using a Compression Bridge Assembly (Fig. 1) according to JIS R $1607^{18)}$. Extension of precrack was monitored under microscopic observation with the aid of transillumination, and the depth of precrack was confirmed under the microscope using dye penetration. All specimens were stored in a desiccator at room temperature or in water at $37^{\circ} \mathrm{C}$ for 48 hours before the fatigue test.

Fatigue crack propagation test

Fatigue crack propagation tests were performed in

Table 1 Resin composites and ceramics investigated in this study.

\begin{tabular}{|c|c|c|c|c|c|}
\hline Code & $\begin{array}{l}\text { Product name } \\
\text { (manufacturer) }\end{array}$ & Composition & $\begin{array}{l}\text { Filler/crystal } \\
\text { content (vol\%) }\end{array}$ & $\begin{array}{l}\text { Mean particle size of } \\
\text { filler/crystal }(\mu \mathrm{m})\end{array}$ & Lot No. \\
\hline \multicolumn{6}{|c|}{ Resin composites } \\
\hline APX & $\begin{array}{c}\text { Clearfil AP-X } \\
\text { (Kuraray, Osaka, Japan) }\end{array}$ & $\begin{array}{l}\text { Bis-GMA, TEGDMA, } \\
\text { Barium glass, } \\
\text { Silica }\end{array}$ & $68-71$ & 3 & 303 \\
\hline PAE & $\begin{array}{c}\text { Palfique Estelite } \\
\text { (Tokuyama, Tokyo, Japan) }\end{array}$ & $\begin{array}{l}\text { Bis-GMA, TEGDMA, } \\
\text { Barium zirconia filler, } \\
\text { Organic filler }\end{array}$ & 71 & $\begin{array}{l}\text { Inorganic filler: } 0.2 \\
\text { Organic filler: } 40\end{array}$ & EU115 \\
\hline \multicolumn{6}{|c|}{ Dental ceramics } \\
\hline EMP & $\begin{array}{c}\text { IPS Empress } \\
\text { (Ivoclar Vivadent, Schaan, } \\
\text { Liechtenstein) }\end{array}$ & $\begin{array}{l}\mathrm{SiO}_{2}, \mathrm{Al}_{2} \mathrm{O}_{3}, \mathrm{~K}_{2} \mathrm{O} \\
\text { Leucite crystals }\end{array}$ & 24 & $1-5$ & 1474 \\
\hline DCR & $\begin{array}{c}\text { Dicor } \\
\text { (Dentsply International, } \\
\text { York, PA, USA) }\end{array}$ & $\begin{array}{l}\mathrm{K}_{2} \mathrm{O}-\mathrm{MgF}_{2}-\mathrm{MgO}-\mathrm{SiO}_{2} \\
\text { Fluoromica crystals }\end{array}$ & 65 & 2 & 94708 \\
\hline
\end{tabular}


general accordance with ASTM E647-93 ${ }^{19)}$ using an electro servohydraulic testing machine (Servopulser EHF FD01, Shimadzu Co., Kyoto, Japan) in both dry and aqueous environments. The test under dry condition was conducted at room temperature $\left(23^{\circ} \mathrm{C}\right)$, while that under aqueous condition was conducted in a circulating water bath (Thermo Supplier EZL-80, Taitek Co., Saitama, Japan) at $37^{\circ} \mathrm{C}$.

Sinusoidal cyclic loading was applied at a frequency of $10 \mathrm{~Hz}$ with a mean stress ratio ( $\mathrm{R}=\mathrm{Kmin} / \mathrm{Kmax}$ ) of 0.1 . Length of the vertical crack propagation was measured every 60 seconds by an optical microscope (Traveling Microscope Type A, Shimadzu Co.) at a magnification of $\times 40$ with the aid of trans-and reflecting illumination. The fatigue test came to a completion when the crack propagated through the whole vertical surface of the specimen.

Resistance to fatigue crack propagation was expressed in terms of fatigue crack growth rate ( $d \mathrm{a} /$ $d \mathrm{~N})$ and crack tip stress intensity factor range $(\Delta \mathrm{K})$, as defined by the theory of linear elasticity and shown in the following equation ${ }^{20}$ :

$$
d \mathrm{a} / d \mathrm{~N}=C(\Delta \mathrm{K})^{\mathrm{m}}
$$

where $a$ is the crack length, $N$ the number of cyclic loads, $C$ and $\mathrm{m}$ the experimentally determined scaling constants, and $\Delta \mathrm{K}$ the variation in stress intensity
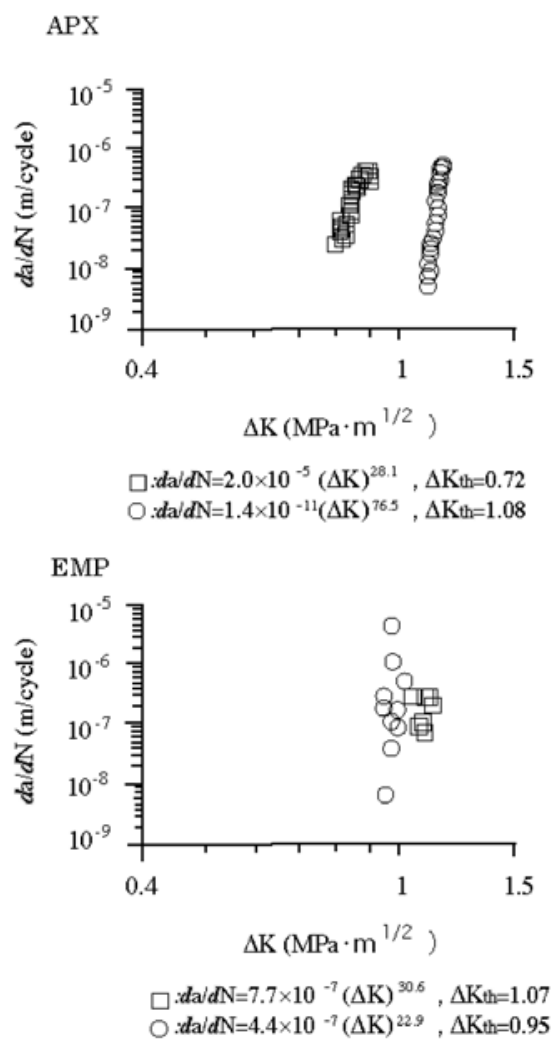

factor in a cycle-which is as shown below:

$$
\Delta \mathrm{K}=\mathrm{Kmax}-\mathrm{Kmin}
$$

As for fatigue fracture resistance, it was expressed in terms of fatigue crack growth threshold $\left(\Delta K_{\text {th }}\right)$ - which was the asymptotic value of $\Delta K$ at which $d \mathrm{a} / d \mathrm{~N}$ approached zero. $\Delta \mathrm{K}_{\text {th }}$ was given as the $\Delta \mathrm{K}$ value corresponding to a fatigue crack growth rate of $10^{-10} \mathrm{~m} /$ cycle.

\section{Fractographic examination}

After the fatigue crack propagation test, a vertical compression load was applied by the servohydraulic testing machine until a complete fracture occurred. Fractured surfaces were then observed by scanning electron microscopy (JSM9 840A, JEOL Ltd., Tokyo, Japan) at magnifications ranging from $\times 50$ to $\times$ 1500 after sputter-coating with a gold-palladium alloy.

\section{RESULTS}

Characteristics of fatigue crack growth in resin composites and dental ceramics under dry and aqueous conditions are shown in Fig. 2. The $\mathrm{m}$ values of resin composites and dental ceramics were in the ranges of 11.6-76.5 and 22.9-54.6 respectively. The
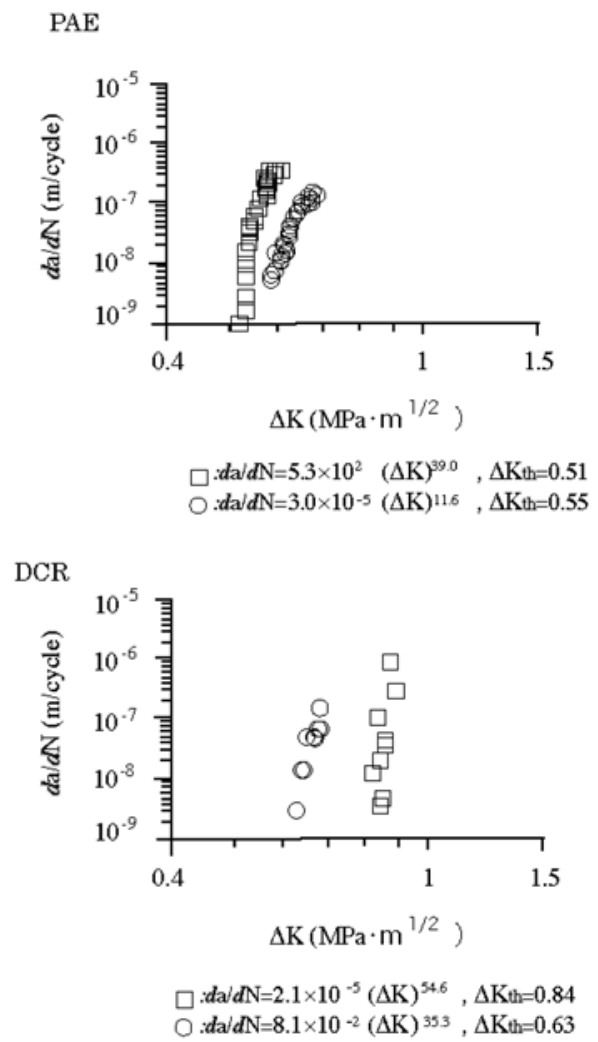

Fig. 2 Characteristics of fatigue crack propagation in resin composites and dental ceramics under dry $(\square)$ and aqueous $(\bigcirc)$ conditions. 


\section{AP-X}
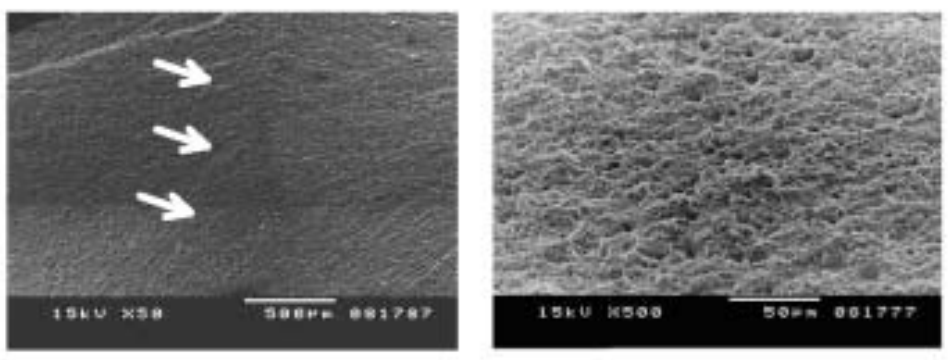

PAE
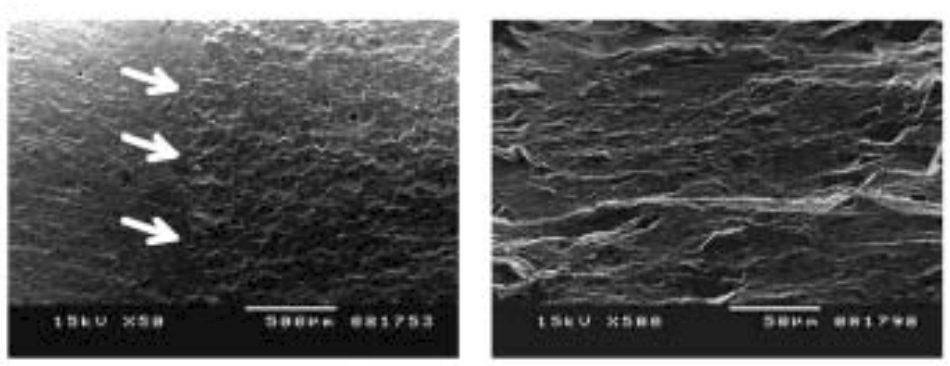

Empress
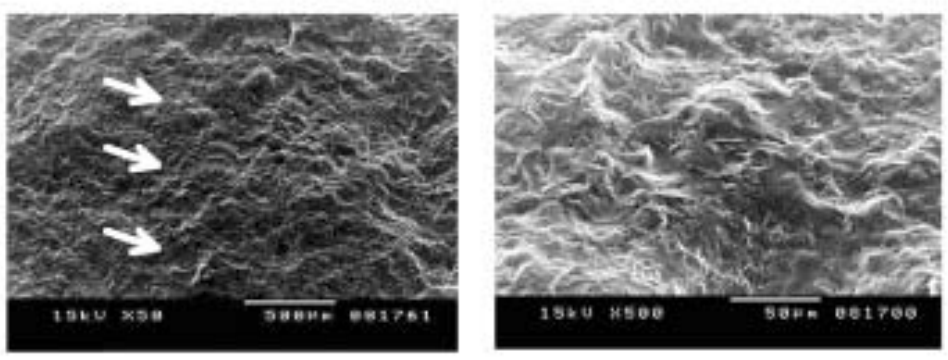

Dicor
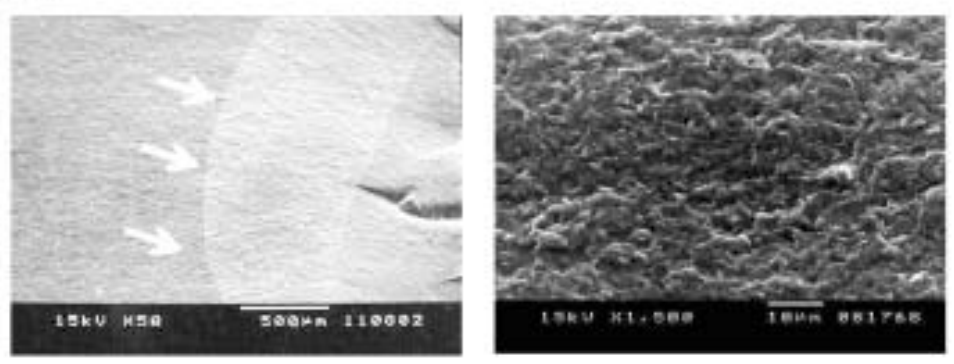
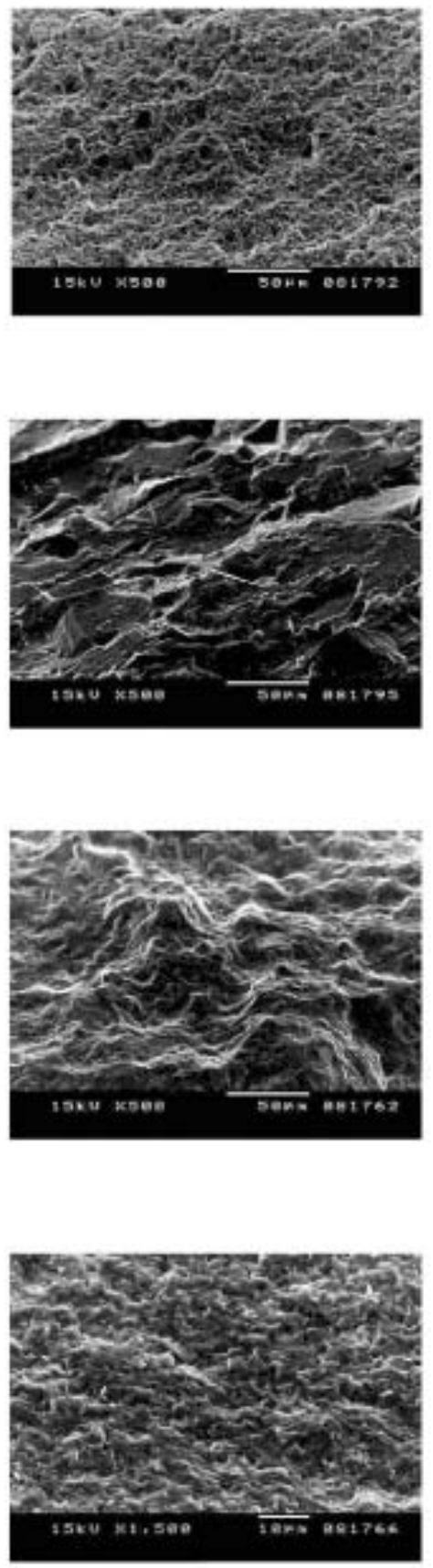

Fig. 3 Fatigue fracture and unstable fracture surfaces of resin composites and dental ceramics under aqueous condition. Left: area including the boundary $(\rightarrow)$ between fatigue and unstable fractures at low magnification; middle: brittle fracture surface at high magnification; right: fatigue fracture surface at high magnification.

Boundary between the fatigue and unstable fractures was evident; as well the fatigue fracture surface rougher than the unstable fracture surface in both composites and ceramics. Filler particles were clearly observed on the fatigue fracture surface in both resin composites. With APX, inorganic fillers with a diameter of $5 \mu \mathrm{m}$ were exposed on the fatigue fracture surface. With PAE, fatigue fracture pathway was found through the prepolymerized organic fillers with diameter of $40 \mu \mathrm{m}$ in some areas. Fluoromica crystals in DCR were detected all over the fatigue fracture surface, while leucite crystals in EMP were not. 
$\Delta K_{\text {th }}$ values of resin composites and ceramics were calculated to be 0.51-1.08 and 0.63-1.07 respectively. Resin composites showed greater $\Delta K_{\text {th }}$ values under aqueous condition than under dry condition, whereas ceramics had smaller $\Delta \mathrm{K}_{\text {th }}$ values under aqueous condition than under dry condition. In particular, the $\Delta K_{\text {th }}$ values in dry and aqueous conditions differed remarkably for APX and DCR.

Fractographic examination revealed no morphological differences in fracture surface between dry and aqueous environments. Representative fatigue fracture and unstable fracture surfaces of composites and ceramics under aqueous condition are shown in Fig. 3. Boundaries between fatigue and unstable fractures were evident, and fatigue fracture surfaces were rougher than unstable fracture surfaces in both composites and ceramics.

Filler particles were clearly observed at the fatigue fracture surfaces of both resin composites. In APX, inorganic fillers with a diameter of $5 \mu \mathrm{m}$ were exposed on the fatigue fracture surface. In PAE, fatigue fracture pathway was found through the prepolymerized organic fillers with a diameter of 40 $\mu \mathrm{m}$ in some areas. In DCR, fluoromica crystals were detected all over the fatigue fracture surface, while leucite crystal sin EMP were not.

\section{DISCUSSION}

The fatigue resistance of dental ceramics is commonly expressed in terms of both crack initiation and propagation, since fatigue tests are generally conducted using plain specimens without precracks ${ }^{5.8}$. This has been so because it is difficult to initiate a precrack in preparation for the fatigue test due to the extreme brittleness of dental ceramics. However, internal and external microflaws are inevitable in dental restoratives. As such, fatigue crack growth test using specimens with a precrack is considered more appropriate for evaluating clinical fatigue resistance. In the present study, crack initiation was successfully achieved by machining pyramid-shaped starter notches, and a precrack thereby obtained by propagating a crack from this region by applying compressive force using a Compression Bridge Assembly.

When cyclic compressive force was applied after storing resin composites in water or aqueous fluids for defined periods of time, the fatigue fracture resistance decreased compared with that under dry condition $^{10-12,17)}$ - findings which were consistent with the results of our previous study ${ }^{13}$. Reasons for the inferior fatigue resistance of composites after storage in water were considered to be due to hydrolyses of the resin matrix and filler-matrix interface, arising from water absorption.

Contrary to common perception, the present study indicated that the fatigue fracture resistance of resin composites increased under aqueous condition a finding consistent with our previous study too ${ }^{13)}$. A similar increase in fracture resistance of a carboncoated graphite composite was also reported when specimens were completely immersed in water ${ }^{21}$. The increased fracture resistance of composites under aqueous condition in the present study could be explained by the following phenomena due to water absorption by the resin matrix. Water absorption encourages plasticization of the resin matrix-resulting in decreased brittleness of the composites, as well as releases the internal tensile stress generated during polymerization shrinkage and the residual compressive stress at the crack tip. These phenomena then contributed to the retardation of crack propagation in composites under aqueous condition, either independently or in combination.

It is important to be aware of the adverse effect of water on fatigue resistance of composites - although it depends on the experimental conditions. While toughening of resin composites under aqueous condition was observed in the present study, long-term deterioration of composites due to water absorption has also been reported ${ }^{15)}$. In other words, interaction between these antagonistic mechanisms of retardation of crack propagation versus hydrolysis of the resin matrix can proceed simultaneously in resin composites, and the effect of such interaction on fatigue behavior after long-term water immersion requires further investigation.

In both composites, filler particles were clearly observed on the fatigue surface, suggesting that fatigue crack propagation pathway was present at the matrix-filler interface. In PAE, the crack pathway penetrated the organic fillers in some areas (Fig. 3), and their $\Delta K_{\text {th }}$ values were remarkably smaller than those of APX, regardless of the environmental condition. These observations indicated that organic fillers were less effective for retarding crack propagation in resin composites due to their inferior mechanical properties. Filler particle size in resin composites has been reported to be one of the critical factors for retarding fatigue crack growth ${ }^{13,22)}$. The results of the present study suggested that filler components-organic versus inorganic filler particles - also played a critical role against fatigue fracture resistance in composites.

Crystals in ceramics contribute to retardation of fatigue crack growth via the mechanisms of crack bridging, crack deflection, and welding-either independently or in combination ${ }^{23)}$. The leucite crystals in EMP could be considered to be useful for retarding cracks, despite their low content (24\%), since EMP retained relatively high $\Delta \mathrm{K}_{\text {th }}$ values even under aqueous condition. Further, fractographic examination revealed that leucite crystals could hardly be detected 
on the fatigue fracture surface, and that the glass matrix still adhered to the crystals. This cohesive fracture thus suggested firm crystal-matrix adhesion, which could render optimal strength properties against fatigue. In contrast, fluoromica crystals were observed all over the fatigue fracture surface of DCR, suggesting predominant adhesive failure between the crystals and the glass phase.

Slow crack growth kinetics are known to be strongly influenced by the amount and composition of the glass phase in a ceramic microstructure ${ }^{24)}$. Stress corrosion preferentially occurs in silicate-based ceramics, resulting in bond rupture due to hydrolysis ${ }^{16)}$. The binding of Si-O-Si at the tip of a crack splits into $\mathrm{Si}-\mathrm{OH}$ and $\mathrm{OH}-\mathrm{Si}$ under aqueous conditions with tensile stress. In the present study, bonding strength at the crystal-glass interface in DCR appeared to be less durable against fatigue fracture, particularly under the aqueous condition, despite a high crystal content (65\%). This finding thus suggested that firm bonding between glass matrix and crystals was more critical for fracture resistance than the crystal content.

Taken together, the results of the present study demonstrated that water exerted different effects on fatigue fracture resistance in resin composites and dental ceramics. For resin composites, the bonding between the resin matrix and filler particles played a critical role against fatigue resistance, and likewise the bonding between the glass phase and crystals in dental ceramics.

\section{ACKNOWLEDGEMENTS}

This study was supported in part by a Grant-in-aid for Scientific Research (No. 16390546) from the Japan Society for the Promotion of Science and by the 21st Century COE Program at Osaka University Graduate School of Dentistry.

\section{REFERENCES}

1) Braem M, Lambrechts P, Vanherle G. Clinical relevance of laboratory fatigue studies. J Dent 1994; 22:97-102.

2) Baran GR, Boberick KG McCool JI. Fatigue of restorative materials. Crit Rev Oral Biol Med 2001; 12:350-360.

3) Morena R, Beaudreau GM, Lockwood PE, Evans AL, Fairhurst CW. Fatigue of dental ceramics in a simulated oral environment. J Dent Res 1986; 65:993-997.

4) White SN. Mechanical fatigue of a feldspathic porcelain. Dent Mater 1993; 9:260-264.

5) White SN, Li CZ, Yu Z, Kipnis V. Relationship between static chemical and cyclic mechanical fatigue in a feldspathic porcelain. Dent Mater 1997; 13:103-110.

6) Fairhurst CW, Lockwood PE, Ringle RD, Twiggs SW.
Dynamic fatigue of feldspathic porcelain. Dent Mater 1993; 9:269-273.

7) Jung YG, Peterson IM, Kim DK, Lawn BR. Lifetimelimiting strength degradation from contact fatigue in dental ceramics. J Dent Res 2000; 79:722-731.

8) Lohbauer U, Petschelt A, Greil P. Lifetime prediction of CAD/CAM dental ceramics. J Biomed Mater Res 2002; 63:780-785.

9) Anusavice KJ. Mechanical properties of dental materials. In: Phillips' science of dental materials 1996; 49-74.

10) Montes GM, Draughn RA. Slow crack propagationin composite restorative materials. J Biomed Mater Res 1987; 21:629-642.

11) Truong VT, Tyas MJ. Prediction of in vivo wear in posterior composite resins: a fracture mechanics approach. Dent Mater 1988; 4:318-327.

12) Truong VT, Cock DJ, Padmanathan M. Fatigue crack propagation in posterior dental composites and prediction of clinical wear. J Appl Biomater 1990; 1:21-30.

13) Takeshige F, Kawakami Y, Hayashi M, Ebisu S. Fatigue behavior of resin composites in aqueous environments. Dent Mater 2006 (in press).

14) Choi SR, Salem JA. Slow crack growth of indent cracks in glass with and without applied stress. Mater Sci Eng 1992; A149:259-264.

15) Braem MJA, Lambrechts $P$, Gladys $S$ Vanherle G. In vitro fatigue behavior of restorative composites and glass ionomers. Dent Mater 1995; 11:137-141.

16) Charles RJ. Dynamic fatigue of glass. J Appl Phys 1958; 29:1657-1662.

17) McCool JI, Boberick KG, Baran GR. Lifetime predictions for resin-based composites using cyclic and dynamic fatigue. J Biomed Mater Res 2001; 58:247-253.

18) Japanese Industrial Standard (JIS) R 1607. Standard method for measurement of fracture toughness of fine ceramics, Japanese Standards Association, 1995.

19) ATSM E647-93. ASTAM standard method for measurement of fatigue crack growth rates, Am Soc Test Mater, 1993.

20) Paris PC, Gomez MP, Anderson WP. A rational analytic theory of fatigue. Trends Engin 1961; 13:9-14.

21) Ritchie RO, Dauskardt RH, Yu W. Cyclic fatiguecrack propagation, stress-corrosion, and fracturetoughness behavior in pyrolytic carbon-coated graphite for prosthetic heart valve applications. J Biomed Mater Res 1990; 24:189-206.

22) Spanoudakis J, Young R. Crack propagation in a glass particle-filled epoxy resin. Part 1: Effect of particle volume fraction and size. J Mater Sci 1984; 19:473-486.

23) Ritchie RO. Mechanisms of fatigue crack propagation in metals, ceramics and composites: Role of crack-tip shielding. Mater Sci Eng 1988; 103A:15-28.

24) Wiederhorn SM. Influence of water vapor on crack propagation in soda-lime glass. J Am Ceram Soc 1967; 50:407-414. 